\title{
ENTRE O OLHAR E O DIZER: PALAVRA E IMAGEM NAS OBRAS DE MARIO CESARINY E ALEXANDRE O'NEILL
}

Marcus Rogério Tavares Sampaio Salgado

(UnB)

\section{RESUMO}

Nosso objetivo é um estudo panorâmico das relações entre poesia, visualidade e imagem nas obras dos poetas portugueses Mario Cesariny de Vasconcelos e Alexandre O'Neill.

PALAVRAS-CHAVE: Poesia; Visualidade; Imagem

\section{ABSTRACT}

This article presents a panoramic study on the relations between poetry, visuality and image in the poetic works by the portuguese poets Mario Cesariny de Vasconcelos and Alexandre O'Neill.

KEYWORDS: Poetry; Visuality; Theory of Image 
O foco do presente artigo é a abordagem das relações entre palavra e imagem na obra dos poetas portugueses Mario Cesariny de Vasconcelos e Alexandre O’Neill, tentando compreender, a partir desse movimento inicial, as dinâmicas estéticas que poesia e visualidade podem manifestar em conjunção.

Com tal objetivo, definimos um corpus capaz de representar os pontos de culminância da obra de cada autor, onde se verificam problematizadas, de uma maneira ou de outra, as relações entre palavra e imagem enquanto situações constitutivas do texto literário.

Estes pontos de culminância, a nosso ver, seriam, no caso de Cesariny, o livro de poemas Primavera autônoma das estradas (1980) e o ensaio de crítica de arte Vieira da Silva, Arpad Szenes, ou O Castelo Surrealista (1984), e, no caso de Alexandre O’Neill, A ampola miraculosa (1948) e Divertimento com sinais ortográficos (1960).

Nestas quatro obras encontramos as relações entre artes visuais e literatura alçadas ao papel de protagonistas no próprio processo de criação, sendo possível detectar, entre si, continuidades e rupturas no tocante a tal elemento comum.

De imediato, o que se ressalta nas obras de Mario Cesariny e Alexandre O’Neill - e, em certa medida, justifica a aproximação ora tentada - é o fato de explorarem os domínios da criação literária até as fronteiras com as artes visuais e, de par com esse elemento formal renovador, encontrarem lugar próprio no interior da tradição poética portuguesa. É assim que em suas obras desdobram-se planos de intertextualidade diretamente estabelecidos no interior da poesia portuguesa - já que ambos eram grandes leitores de poesia, flagrando-se aí aberta intenção de diálogo com poetas de períodos os mais diversos, como Nicolau Tolentino e Cesário Verde (caso de O’Neill) ou Fernando Pessoa (com os quais os dois poetas estabelecerão diálogos em diferentes platôs de significação) -, sem se esquecer de retomar, ainda, a discussão sobre as possibilidades existentes no território que se estende entre palavra e imagem.

Para a compreensão eficaz das estratégias agenciadas no plano estético pelas obras de Cesariny e O'Neill, teremos que necessariamente revisitar as tentativas de sistematização das relações possíveis entre palavra e imagem. Tais relações remetem à cena da origem da própria linguagem escrita, do que fazem prova as expressões verbais em forma pictográfica. A bem da verdade, esta dinâmica da textualização do espaço figural e da figuração do espaço textual (como propõe Lyotard em seu estudo sobre as relações entre discurso e imagem) não parece ter sido interrompida, como se percebe das imbricações entre icônico e verbal encontradas não apenas em livros e pinturas como também em tapeçarias, mosaicos, Livros de Horas, cartazes de propaganda, histórias em quadrinhos, filmes etc.

Até mesmo por conta da produção ininterrupta de híbridos icônico-verbais nos domínios da indústria cultural, as relações entre palavra e 
imagem, entre linguagem verbal e linguagem icônica têm sido objeto de estudos os mais diversos, sob linhas estéticas e ideológicas igualmente distintas.

Para além das diversas linhagens teórico-críticas atuantes na contemporaneidade, sabemos que as relações entre arte poética e arte visual já haviam sido discutidas na Antiguidade. Segundo Plutarco (apud MUHANA, 2002, p. 12), Simônides de Ceos - importante poeta do período arcaico grego - já teria formulado a equivalência entre poesia e pintura, ao qualificar a poesia como pintura que fala e a pintura como poesia silenciosa. Aristóteles estava atento à possibilidade de homologias entre as artes quando, na abertura da Poética, aproxima poesia e música enquanto artes da mimesis, em que pesem os meios, os objetos e os modos diversos de cada arte. Ainda na Poética, Aristóteles adverte que "os poetas imitam homens melhores, piores ou iguais a nós, como o fazem os pintores: Polignoto representava os homens superiores; Pauson, inferiores; Dionísio representava-os semelhantes a nós" (ARISTÓTELES, 2003, p. 104), aproximando, portanto, poesia e pintura a partir da perspectiva da imitação. Sobre as possibilidades dessa homologia se deteve também Horácio na célebre Epistula ad Pisones, onde encontramos a síntese ut pictura poesis, cunhada para aferir a possibilidade de comparativismo entre os pressupostos norteadores e as práticas características de artes distintas como a poesia e a pintura. $\mathrm{Na}$ abertura desse texto que acabaria sendo conhecido como sua "poética", Horácio, ao dispor-se a refletir sobre o trabalho do poeta, sinaliza para o fato de que a premência por ordem e unidade que preside a organização estrutural de um poema seria da mesma natureza daquela que coordena a criação pictórica, chegando, mais adiante, à síntese aludida: "Poesia é como pintura" (HORÁCIO, 1981, p. 65).

As reflexões em torno da homologia entre poesia e pintura (que se insere, por sua vez, em um quadro mais amplo sob cuja moldura se debatem as possibilidades de homologia entre as diversas artes) prosseguiram durante o Renascimento. Leonardo da Vinci, no famoso tratado "O parago$n e$ ”, retomou a discussão aberta pelos clássicos, ao afirmar que "a pintura é uma poesia muda e a poesia uma pintura cega; e tanto uma quanto a outra tentam imitar a natureza segundo seus limites, e tanto uma quanto a outra permitem demonstrar diversas atitudes morais" (apud LICHTENSTEIN, 2005,p. 20). Embora se lance do mesmo ponto de partida dos clássicos, da Vinci, entretanto, avança em suas reflexões ao ponto de arriscar uma hierarquia entre as duas artes, reconhecendo no signo visual possibilidades mais amplas.

O debate se desdobra ao longo dos séculos seguintes. Lessing, no prefácio e ao longo de Laocoonte - considerada uma das obras mais importantes do século XVIII em matéria de crítica estética - discute em detalhes as relações entre as duas artes, ao ponto de ostentar o subtítulo "sobre as fronteiras da pintura e da poesia”. Nesse texto capital para a construção crítica da modernidade estética ocidental, Lessing não apenas reconhece a precedência de uma série de investigadores sobre o tema, como ainda 
refuta os pressupostos críticos que presidem seus juízos. Para Lessing, a aproximação entre as duas artes - sobretudo quando feita sem atentar para as especificidades de expressão que as caracterizam individualmente - trazia em si riscos: "ela gerou na poesia a mania da descrição e na pintura o alegorismo; assim, procurou-se fazer da primeira uma pintura falante, sem se saber propriamente o que ela pode e deve pintar, e da segunda um poema mudo, sem se ter refletido em que medida ela pode expressar conceitos universais sem se distanciar da sua determinação e se transformar num tipo de escrita arbitrária" (apud LICHTENSTEIN, 2004, p. 84-85).

Diderot também se ocupou do assunto e, na opinião de Arnaud Buchs, "a aproximação analógica das artes atravessa e, de uma certa maneira, estrutura toda a obra de Diderot" (BUCHS, 2010, p. 17). A Carta sobre os surdos-mudos para uso dos que ouvem e falam, por exemplo, é escrita em resposta a um texto do abade Charles Batteux, que propunha analisar as "belas-artes reduzidas a um mesmo princípio" (BUCHS, 2010, p. 17). Para Diderot, faltava rigor nas abordagens que eram habituais sobre o assunto. Em seu entendimento, mais do que artifícios retóricos de efeito fácil, era necessário, sim, "reunir as belezas comuns da poesia, da pintura, da música, mostrar-lhe as analogias, explicar como o poeta, o pintor e o músico produzem a mesma imagem, captar os emblemas fugazes de sua expressão, examinar se há similaridade entre esses emblemas etc" (DIDEROT, 1993, p. 57). Ao clamar pela explicação sobre "como cada arte imita a natureza num mesmo objeto" (DIDEROT, 1993, p. 58), Diderot traça o percurso a ser cumprido pelos investigadores que se dedicarem a elucidar as correspondências entre as artes: estar atento às possibilidades de correspondência, sem ignorar as especificidades de cada uma.

A linha de argumentação de Lessing e Diderot ecoaria, no século XIX, na crítica de arte de Baudelaire. Num texto do Salão de 1846 em que trata de Delacroix e Victor Hugo, o poeta das Flores do mal adverte que "essa necessidade de encontrar a qualquer preço pontos de comparação e analogias entre as diferentes artes, leva, muitas vezes, a estranhos equívocos" (apud LICHTENSTEIN, 2004, p. 104). A despeito de professar, no plano cósmico, as "correspondências" swedenborguianas, Baudelaire prescrevia cautela ao se ponderar sobre as correspondências entre as artes consideradas no plano estritamente estético.

Na opinião de Arnaud Buchs, há uma linha reta que liga Lessing, Diderot e Baudelaire e nela devemos procurar o processo de desmontagem da retórica clássica que a modernidade estética propõe no tocante às relações entre as diversas artes. Segundo Buchs, em Laocoon Lessing "pôs termo definitivo aos erros da doutrina do ut pictura poesis" (BUCHS, 2010, p. 7), ao reconhecer a existência de diferenças essenciais (e intransponíveis) entre as duas artes, já que, na perspectiva que preside as reflexões do poeta e filósofo alemão, "a pintura é por essência uma arte do espaço, enquanto a poesia, e mais genericamente a literatura, repousa fundamentalmente sobre o tempo" (BUCHS, 2010, p. 7). 
Ao longo do século XX, as discussões foram reacendidas pela teoria e prática preconizada pelos movimentos de vanguarda, ocupados em investigar, em ambos os planos, as possibilidades de intermedialidade. Essa preocupação se acentuou com as vanguardas tardias, de que fazem prova, no campo da poesia de língua portuguesa, o plano-piloto da Poesia Concreta (com sua busca por uma poesia verbivocovisual) e a chamada Poesia Experimental portuguesa dos anos 60.

Entre os eruditos que, ao longo dos últimos cinquenta anos, se dedicaram à pesquisa sistemática das relações entre palavra e imagem, encontramos Mario Praz, Herbert Read, Erwin Panofsky, Michel Butor, W. J. T. Mitchell e Arnaud Buchs, que dão uma amostragem impressiva do espectro de produção sobre o tema no âmbito das discussões teóricas, sem deixar de representar com eficiência essa multiplicidade de matizes na crítica contemporânea, a que se poderia acrescentar os trabalhos sobre o tema elaborados por teóricos e críticos de língua portuguesa - como Eduardo Lourenço (O espelho imaginário: pintura, anti-pintura, não-pintura), E. M. Mello e Castro (Po-Ex: Textos teóricos e documentos da poesia experimental portuguesa), Ana Hatherly (Interfaces do Olhar), Décio Pignatari (Semiótica e literatura), Vilém Flusser (Filosofia da caixa preta), Uilcon Pereira (Escritema e figuralidade nas artes plásticas contemporâneas) e Sergio Lima (A aventura surrealista).

Como se percebe, as questões implícitas na proposição ut pictura poiesis não se esgotaram na Antiguidade, sendo mesmo lícito afirmar que a busca por uma compreensão mais ampla das relações entre poesia e artes visuais atravessa toda a modernidade, já que, continuamente, novas respostas emergiram para a questão original atinente às relações entre imagem e palavra, como já fora proposta, em linhas gerais, por Simônides de Ceos, Aristóteles e Horácio. Gradativamente, o entusiasmo fácil pelo paralelismo entre as artes foi perdendo espaço para uma visão crítica menos condescendente e mais atenta às especificidades (não apenas no plano filosófico, enquanto formas de representação, mas também no âmbito técnico) de cada arte, uma visada que problematiza essa relação, sem, contudo, deixar de reconhecer as possibilidades de interpenetração entre as diversas linguagens artísticas.

É por essa razão que, ainda que expressas de forma fragmentária e necessariamente inconclusa, as reflexões que nos chegam tanto da Antiguidade como da Modernidade sobre as relações entre signo verbal e signo visual no campo das artes plásticas e da poesia configuram, per si, um mapeamento em que se ressaltam pelo menos três tipos distintos de relações, a saber:

a) discurso sobre uma obra de arte (ékphrasis) ou sobre um artista;

b) vigência de uma estética verbal com proeminência dos elementos imagéticos, como metáforas, símiles etc;

c) tentativa de alcançar uma linguagem híbrida, icônico-verbal, 
obtida mediante formas novas, como a novela gráfica, ou pela metamorfose do signo verbal em signo visual (que, para usar um conceito caro à semiótica de Charles Sanders Peirce, reconheceremos como um processo de iconicização do verbal, o que, em termos de linguística saussuriana, implicaria num deslocamento do foco para o significante).

Vejamos como essas três relações se definem no plano teórico e como se manifestam nas obras de Cesariny e O'Neill.

Para o tipo de relação descrito em "a", revela-se rico o manancial aberto pelos textos de Mario Cesariny, e não apenas no livro que produziu sobre a pintora Maria Helena Vieira da Silva, já que sua obra, considerada na totalidade, revela em abundância elementos aproximativos entre artes visuais e literatura, a ponto mesmo de o autor ter-se aventurado naquele domínio, como prova sua participação, por conta de alguma produção criativa de natureza plástica (desenhos, colagens, pinturas), em exposições coletivas nos anos 50 .

Não é exagero afirmar que, na obra de Cesariny, o icônico e o verbal se encontram num longo abraço mito-poético, caminhando juntos para os domínios do imaginário, jazida que permeia toda criação artística, seja ela feita com palavras ou linhas e cores.

É sob esta prerrogativa de uma intimidade verdadeiramente erótica entre as artes plásticas e a literatura que Cesariny escreveu Arpad Szenes, Vieira da Silva, ou O Castelo Surrealista. A começar, temos um poeta que é também artista plástico e crítico de arte (pois o projeto se enquadraria nos requisitos de uma bolsa que se lhe concedeu para tanto) tentando abordar a obra plástica de um casal de artistas (Arpad Szenes e Maria Helena Vieira da Silva) muito importantes para os meios artísticos tanto portugueses como brasileiros, já que por aqui estiveram durante os anos 40 .

Mas esta não é uma obra que se enquadre nos estereótipos de um texto de crítica de arte, como se poderia pensar do fato de estar abrigada sob estufa institucional, e tampouco encontramos nela qualquer tentativa de subordinação ou redução dos valores plásticos ao discurso. Pelo contrário: além de reconhecer, ao longo de todo o processo, o infinito adiamento de uma posse definitiva da obra para a qual volta seu olhar, o resultado (mesmo que provisório) é um transbordamento entre artes plásticas, poesia e discurso crítico, como prova a longa correspondência que Cesariny manteve com o casal. À sombra de tais circunstâncias é que floresceu Arpad Szenes, Vieira da Silva, ou O Castelo Surrealista e é rentável que se confronte a articulação tentada nessa obra com a noção clássica de ékphrasis.

Conhecida pela retórica clássica, a ékphrasis é um artifício linguístico pelo qual uma arte se refere a outra, tentando reter - no caso da literatura, por meio de um uso específico da linguagem verbal - os valores e essências intrínsecos a esta outra arte. Encontraremos seu uso em todos os recortes epocais da historiografia literária, de Homero a Dostoievski, passando por Luciano de Samósata, barrocos, românticos e surrealistas. 
Como se vê, a ékphrasis se impõe para além de restrições não apenas epocais, como também estilísticas e é uma eficiente porta de entrada para o estudo das relações entre artes plásticas e literatura.

A tradição anglófona tem trazido significativos aportes à investigação sobre a ékphrasis, com lastro majoritário fornecido pelo scholar W. J. T. Mitchell, que tem conduzido, desde os anos 1970, longa e fecunda pesquisa sobre a teoria da imagem, considerada, sob viés interdisciplinar e num espectro de máxima ressonância semântica, simultaneamente enquanto representação mental e enquanto figura retórica.

Um dos capítulos de sua obra mais importante sobre o tema (Picture Theory: Essays on Verbal and Visual Representation) trata especificamente da ékphrasis, vista a partir dos mirantes estético, psicológico e ideológico. Nesse capítulo, o scholar americano desenvolve conceitualmente a ékphrasis enquanto utopia, uma vez que, como frisa Mitchell, a ékphrasis seria, em última instância, a consumação do sonho impossível de um intercâmbio e de um trânsito direto entre signos verbais e signos visuais, sem hierarquização ou redução.

Ao ler a correspondência entre Cesariny e o casal de artistas, percebe-se que, em determinado ponto, o objeto crítico deixou de ser apenas objeto e passou a revestir-se de figurações míticas (o que é reforçado pela presença do castelo surrealista no título da obra), já que Vieira da Silva e Arpad Szenes aparecem antes como elementos de um matrimônio não carnal, mas alquímico, testemunhado por Cesariny, aqui como voyeur supremo, que, ao olhar para as obras de um e de outra, os vê nus porque os vê em alma. Como escreveria o próprio Cesariny, "a alma sexo do homem" (CESARINY, 1980, p. 127).

As conexões entre imagem e mito despertadas na escrita de Cesariny assim se produzem por conta da experiência de alteridade que nela se faz implícita. Vivemos em sociedades onde as imagens técnicas (na terminologia de Vilém Flusser) têm preponderância e onde, a partir de uma articulação binária do mundo e do pensamento, as imagens são vistas em relação de oposição às palavras. Assim, quando a palavra se volta para a imagem, tentando apreender sua dinâmica, temos aquilo que se poderia chamar de encontro com 'outros' semióticos, para permanecermos sob o enquadramento teórico proposto por W. J. T. Mitchell. Para este autor, as diferenças entre texto e imagem podem ser lidas de forma semelhante à que lemos a relação entre eu e o outro. Segundo o mesmo teórico, entre palavra e imagem teríamos nada menos que o encontro entre modos de representação rivais, cuja aproximação, de plano, gera estranhamentos entre si. É por isso que, para Mitchell, ao produzir "outros textuais" (MITCHELL, 2009, p. 142), a ékphrasis trabalha, em seu núcleo duro, com a experiência da alteridade, ostentando a marca específica de tentar detectar tal experiência no interior das figuras óticas e discursivas que compõem o próprio conhecimento. 
Definitivamente, o que Mario Cesariny tenta em Vieira da Silva, Arpad Szenes, ou O Castelo Surrealista é uma utopia de metalinguagem, onde a ékphrasis se alça à condição de princípio universal da poética. É uma tentativa de estabelecer não hierarquias e sim vasos comunicantes entre palavra e imagem, alentada pelo que W. J. T. Mitchell chama de "esperança utópica da ékphrasis" (MITCHELL, 2009, p. 155): a esperança de uma livre transferência e de uma reciprocidade entre o verbal e o visual.

Essa sinalização utópica é, contudo, revertida por Cesariny com as "memórias descritivas" apostas à obra plástica de Marie José Paz, no livro Figuras e fugurações. Em resposta a dez trabalhos de Marie José, seu marido, o poeta Octavio Paz, escreveu dez poemas, aos quais ela respondeu com novas obras visuais, num circuito de retroalimentação entre poesia e artes plásticas. O resultado final foi um livro composto por reproduções dos trabalhos da artista mexicana, a que seguem os textos diretamente relacionados de Octavio Paz (revelando aspectos da criação das obras plásticas, num desvelamento erótico pelo qual olhar e dizer procuram uma equivalência imediata). Para a tradução portuguesa, acresceu-se, no final do livro, uma série de "memórias descritivas" assinadas por Cesariny, que, ao contrário de Paz, propõe poemas que não se relacionam diretamente com as formas sensíveis das obras plásticas, mas que vêm à tona como ressonâncias delas, numa espécie de anti-ékphrasis.

Na segunda situação a ser analisada - a da predominância de uma estética verbal em que os elementos imagéticos têm preponderância -, nosso foco se volta para um tipo específico de discurso poético, marcado por valores próprios, conforme tentaremos demonstrar.

Segundo o poeta e crítico Ezra Pound, a palavra poética seria carregada de significado por três modos: fanopeia, melopeia e logopeia (POUND, 1970, p. 40). A melopeia diria respeito aos efeitos sônicos da palavra. A logopeia diria respeito à utilização da palavra, pelo poema, em contexto distinto do habitual, trabalhando com a "série de associações intelectuais e emocionais" (LOPES, 1995, p. 105) - ou, como Pound definiria poeticamente, "a dança do intelecto entre as palavras" (POUND, 1988, p. 38). Finalmente, a fanopeia seria a palavra a "lançar uma imagem visual na imaginação do leitor” (POUND, 1970, p. 40). Para usar os termos propostos por Pound, podemos afirmar que a segunda situação que estudaremos é aquela que diz respeito à hegemonia da fanopeia na organização do discurso poético.

Tentar a compreensão do estatuto desse tipo de poesia com ênfase nos valores visuais é tarefa imprescindível para quem se debruça sobre a leitura de poesia, uma vez que, ao lado dos valores específicos da melopeia e da logopeia (que a aproximam, respectivamente, da música e da palavra pensante), a fanopeia atua de forma direta como elemento constituinte do poema, já que ela se faz presente pela "série de imagens desencadeadas pela linguagem poética” (LOPES, 1995, p. 105). 
Nesse ponto, cabe indagar que tipo de imagem é desencadeada pela linguagem poética (sobretudo aquelas obtidas por meio de metáforas e outras figuras comprometidas com a visualidade), pois, como bem frisa Modesto Carone, é evidente que “quando se fala da 'imagem' criada por um poema, o que se tem em mente é o efeito específico de uma modalidade específica de modalidade verbal" (CARONE, 1974, p. 69).

Segundo o mesmo comentador, a imagem criada por um poema funcionaria sob a seguinte forma: "captada pelo olho ou pelo ouvido, é capaz de produzir no leitor vivências de natureza visual, que não devem, entretanto, ser confundidas com as percepções óticas de objetos do mundo físico" (CARONE, 1974, p. 69-70). Além disso, enquanto imagem-sem-suporte ou imagem mental, a imagem poética (portanto, imagem imaginada) se movimenta nos domínios do eidético, originando disso, por sua vez, o potencial ontológico da palavra poética, concebida, aqui, no sentido que lhe dá Eduardo Lourenço, de mediadora "entre linguagem e mundo" (LOURENÇO, 1987, p. 61).

Obviamente, a predominância de valores imagéticos na construção poética não será característica exclusiva de Cesariny, inserindo-o, antes, numa longa tradição da poesia universal (considerada enquanto prática milenar) que tem, como um dos elementos predominantes na composição de seu peso estético específico, a valorização da imagem nos domínios da criação poética. Metáforas, símiles, analogias, etc são figuras conhecidas e reconhecidas pelas tradições poéticas mais diversas, que a elas recorrem, incorporando-as como seu patrimônio, quando o objetivo é ressaltar a potência visual da palavra poética. Isso fica bastante claro no que se refere à metáfora, que, dentre as estratégias de visualidade possíveis no poema, representaria uma das formas mais livres de condicionamento e, ao mesmo tempo, mais ricas de provocar relações indeterminadas (e, por vezes, inéditas) entre os elementos que encadeiam o efeito de significação no poema. Assim, "a relação metafórica permite praticamente uma equivalência entre toda e qualquer significação. Este é, portanto, o maior grau de abertura possível. Para os antigos, a metáfora era a mais rica forma de linguagem figurada” (BRANDÃO, 1989, p. 21).

É nesse sentido que, ao propor uma figuração, a metáfora (enquanto ponto máximo de abertura entre as figuras de linguagem carregadas de visualidade) propõe ao signo verbal que se comporte como um signo visual, pelo menos no tocante à sua potência representacional. Assim, pela metáfora (sobretudo aquela em que a relação entre os elementos provocadores da significação ocorre obedecendo a um grau maior de indeterminação), o símbolo (terceiridade) mimetiza o funcionamento de um ícone (primeiridade), efeito que é obtido pela "relação de semelhança" (BRANDÃO, 1984, p. 19) que a metáfora propõe para esses mesmos elementos deflagradores da significação. Não é por acaso que, nos domínios da semiótica peirceana, noções como semelhança e similaridade identificam a relação que existe entre o ícone e o objeto representado (apud PIG- 
NATARI, 2004, p. 56-57). Peirce chega mesmo a estabelecer uma categoria específica para classificar as metáforas: elas seriam "hipoícones" (apud PIGNATARI, 2004, p. 52), quase ícones, portanto.

Ao propor um grau máximo de abertura possível na relação entre signo verbal e signo visual no tocante à força representacional da palavra poética - a que se seguem a abertura para a indeterminação e o descondicionamento das rotinas linguísticas - e ao encenar a tentativa de metamorfose de um símbolo num ícone, a metáfora também acena para o horizonte utópico, embora em chave diversa daquela proposta pela ékphrasis. Ela nos lembra que, no interior das pré-programações que definem o repertório retórico ou mesmo a "gramática" de uma arte, há sempre espaço para a surpresa e a inovação - quesitos indispensáveis para que se detecte a presença de informação estética, e não mera redundância não-informativa. Não se pode, ademais, esquecer o fato de que Pound atribuía a essa camada de informação visual do poema como sendo universalmente transmissível, sobrevivendo mesmo à tradução (o que nem sempre ocorre com os valores fônicos e ideológicos do poema) - daí que essa camada de informação gerada pelas imagens evocadas pelo poema se constituiria "o elemento mais universal de transmissão da poesia” (LOPES, 1995, p. 107), e, por isso mesmo, "aquela mais indicada para a fundamentação ontológica" (LOPES, 1995, p. 107) da própria poesia. Assim, a poesia com ênfase nos valores fanopaicos acenaria para a possibilidade utópica de uma linguagem poética universalmente transmissível, sem perda de sua força ontológica por conta das condições específicas em que se dá o processo comunicacional.

No que diz respeito a Cesariny, pelas questões envolvidas na escolha por uma poesia com predominância de valores de visualidade se revela também como ele era um atento poeta-leitor, cuja obra não hesita em estabelecer diálogos com o que lhe parece haver de mais compatível na tradição. Disso é exemplo, também, o uso que Cesariny faz de uma forma fixa (o soneto em decassílabos) tida como canônica, já que se trata de forma estabilizada, com grande rentabilidade, há séculos na poesia portuguesa:

não nenhum fim em vista justifica esta hora de carne de compêndio de tudo o que sonhei o grito fica em bailundos que atacam o incêndio

um homem impassível verifica ponto por ponto o nível da cascata que foi de quartzo feldspato e mica agora espanto pênis pus e pata

nem um rato que fosse nem um verme nem um no hemiciclo sopra e geme aqui ou no rossio ou na avenida de berne quem deve não teme 
devoremos o cherne

com dvorjak ao creme.

(CESARINY, 1980, p. 98)

Associado a certa rigidez e pré-determinação plásticas, o soneto é abordado por Cesariny, que ocasionalmente a ele se lança, numa aventura poética em que, ao contrário da ordem lógica da metrificação numérica, encontramos notável grau de desarticulação, a surpreender pelo insólito das imagens engendradas pelas combinações de palavras - por vezes metricamente corretas, porém dotadas de difícil tangibilidade semântica. Tal soneto remete, ao mesmo tempo, aos anfiguri e à poesia pantagruélica, com a diferença de que nestas a univocidade e a clareza do sentido são suspensas em benefício dos valores fônicos, ao passo que em Cesariny, posto que se verifique a presença constante de jogos sonoros, os valores plásticos são predominantes, afirmando-se, mais uma vez, sua individualidade mesmo no quadro mais amplo da tradição. Essa predominância dos aspectos visuais é realçada no poema abaixo reproduzido, onde se acumulam a apropriação pessoal do soneto como estrutura propiciadora de imagens insólitas e a estratégia enumerativa do "inventário":

a velha que vende bananas

o velho roxo de calor

o rapaz que grita sacanas

dêem-me um pouco de amor

a outra viagem por mar

o jovem que já é livreiro

a camionete a esmagar

o túmulo de Sá-Carneiro

o sapato branco do réu

a imobilidade do rato

que roi a ala esquerda do hidro

a mão ereta contra o céu

o céu de súbito contracto

a água a morte a mosca o vidro

(CESARINY, 1980, p. 86).

A bem da verdade, em Cesariny essa hegemonia dos valores visuais se verifica não apenas nos poemas em que formas poéticas tradicionais são desviadas, mas ao longo de toda sua obra. Vide, por exemplo, os poemas "O prestidigitador organiza um espetáculo" ou a série de poemas breves "Visualizações":

Há um piano carregado de músicas e um banco

há uma voz baixa, agradável, ao telefone

há retalhos de um roxo muito vivo, bocados de fitas de todas 
as cores

há pedaços de neve de cristas agudas semelhantes às cristas de água, no mar

há uma cabeça de mulher coroada com o ouro torrencial da sua magnífica beleza

há o céu muito escuro

há os dois lutadores morenos e impacientes

há novos poetas sábios químicos físicos tirando os guardanapos do pão branco do espaço

há a armada que dança para o imperador detido de pés e mãos no seu palácio

há a minha alegria incomensurável

há o tufão que além disso matou treze pessoas m Kiu-Siu

há funcionários de rosto severo e a fazer perguntas em francês há a morte dos outros ó minha vida

há um sol esplendente nas coisas

(CESARINY, 1980, p. 159)

suave

a vela abre

e principia

o dia

ela

que pelo azul

corta

considera e chama

outras velas irmãs para o claro rio

e enquanto

o cais

é um enorme navio

que se nega

e no entanto cumpre

a mais estranha viagem

ela

que parte

vira

para o que abandona

um olhar de brancura

que é toda matemática

singela

da manhã que a inspira

(CESARINY, 1980, p. 49)

Os textos acima transcritos revelam a amplitude dos efeitos visuais que podiam emergir pela palheta de Cesariny, indo do "sol esplendente" ao "azul matinal", atingindo cores e formas mais violentas nos poemas que se pautam diretamente por sua experiência com o surrealismo, de cujas atividades em Portugal tomou parte como artista (assinando declarações co- 
letivas do grupo "Os Surrealistas" e participando da polêmica "I Exposição dos Surrealistas", na sala de projeção da Pathé Baby, em 1949) e historiador (com A Intervenção Surrealista e Textos de afirmação e de combate do movimento surrealista). É o que encontramos nos trechos abaixo, extraídos de "Conto de um sábado de aleluia", "Que concluir" e "A paisagem do relógio branco", respectivamente:

Quem vem lá?

No vale amedrontado as irmãs sobrepostas aceleraram o ritmo da respiração. E, como eco do seu alvoroço inconsciente, retiniam quase em surdina todos os instrumentos de tortura espalhados pelo campo.

Ouviu-se, então, e sabe-se lá de onde vinha, uma canção de embalar:

dorme dorme meu menino

dorme no mar dos sargaços

que mais vale o mar a pino

que a serpente dos meus braços

E então a paisagem alongou-se extraordinariamente, enquanto os cavalos-marinhos acenavam com grandes lenços vermelhos.

(CESARINY, 1980, p. 50).

De uma grande trombeta saiu a mosca - a mosca do pântano onde as cabras lavam as roupas de baixo e os grilos tratam dos ouvidos uns dos outros. A mosca saiu velozmente e pousou na mão que a esperava à saída. Deslizou pela mão, subiu pelo braço e foi dar ao interior de uma víscera extraordinariamente roxa e laboriosa. Aí, tirou as lunetas de vidros fumados, limpou a testa com um lenço quase tão grande como um lençol e começou então, só então, a cantar a ária Os Filhos Perdidos, grande ópera italiana de Mosquito Mosqueteiro, agora entrevado entre quatro rimas de libretos. (CESARINY, 1980, p. 51)

a paisagem do relógio branco talvez dentro do palco talvez fora dele - penso numa janela que dá para certo jardim de três dedos janela que só abre quando faço um sinal de assentimento aos outros pés do imóvel - passo bastante veloz entre almofadas custosas de digerir, água de seltz. fui dar à grande gruta onde todo o maquinismo respira brutalmente de encontro a um animal que de curioso só tem os olhos - uns olhos de curiosidade. outra estranha figura gira continuamente em torno de uma grande mão percorrida por inúmeros insetos de madeira. o maquinismo começou a dar horas - pancadas unilaterais muito sensíveis na minha perna direita que se retraiu por momentos. um grito lindíssimo nasceu na parte superior da con- 
cavidade calcárea e uma rapariga graciosa apesar do cancro que lhe roera o nariz e parte do ventre atou-se vagarosamente ao poste e começou a gritar também. a explosão não tardou a dar-se nas minhas próprias cadeiras. uma grande angústia tomou conta de mim e subindo em balão encontrei uma casa de caridade pública cheia de brilhos com olhos numa série de damas sentadas numa caixa de vidro cortical. (CESARINY, 1980. p. 80-81).

Valores plásticos e imagéticos em predominância também são verificados nos primeiros livros de poesia de Alexandre O’Neill. Como salienta Clara Rocha, uma das preocupações da poética óneilliana é nada menos que o projeto utópico de "libertação total do homem e libertação total da arte" (ROCHA, 1982, p. 12) - começando esta última pela libertação do material artístico, razão pela qual, em sua poesia, a imagem visual tem proeminência.

Para tanto, a poética de O’Neill se apropria de forma bastante particular de técnicas artísticas advindas das artes visuais, como a collage (em poemas onde reina uma diversidade de imagens ligadas por conexões analógicas) ou mesmo a natureza morta (transmutada na forma de "inventários" - como ele intitula os poemas cujos trechos abaixo transcrevemos em que se estabelece uma relação não-convencional entre o olhar e o dizer):

Uma palavra que se tornou perigosa

Um marinheiro dum país "amigo"

Uma pobre mulher tuberculosa

E a mulher orgulhosa que persigo

A velhinha que passa de buíque

Um incêndio prestes a romper

$\mathrm{E}$ as ruas as ruas onde vi

$\mathrm{O}$ que ainda não sei ver

Uma praia elegante um estendal

De belos corpos dolentes

E as últimas mentiras dum jornal

A propósito de fatos recentes

(...)

(O’NEILL, 1981, p. 56)

Um ruído de torneiras em plena missa

Um gato passeado pelo desejo

Uma esposa coberta de caliça

Um despejo

Um congresso que dorme inaugurado

Uma condessa de sovaco triste

Um excremento muito mal logrado

Um mimo a que ninguém assiste 
Um repelente menino Vicente

Posto na vida só p'ra ter juízo

Um incisivo e solitário dente

Carregado de riso

(...)

(O’NEILL, 1981, p. 86).

Um dente d'oiro a rir dos panfletos

Um marido afinal ignorante

Dois corvos mesmo muito pretos

Um polícia que diz que garante

A costureira muito desgraçada

Uma máquina infernal de fazer fumo

Um professor que não sabe quase nada

Um colossalmente bom aluno

Um revólver já desiludido

Uma criança doida de alegria

Um imenso tempo perdido

Um adepto da simetria

Um conde que cora ao ser condecorado

Um homem que ri de tristeza

Um amante perdido encontrado

O gafanhoto chamado surpresa

O desertor cantando no coreto

Um malandrão que vem pé-ante-pé

Um senhor vestidíssimo de preto

Um organista que perdeu a fé

Um sujeito enganando os amorosos

Um cachimbo cantando a marselhesa

Dois detidos de fato perigosos

Um instantinho de beleza

Um octogenário divertido

Um menino colecionando tampas

Um congressista que diz: 'Eu não prossigo'

Uma velha que morre a páginas tantas.

(O’NEILL, 1981, p. 99).

Neste diapasão, torna-se imperioso que se procure entender como se processam na obra de $\mathrm{O}^{\prime}$ Neill as tentativas de articulação de uma linguagem híbrida, em que o icônico e o verbal se interpenetram.

É o caso de A ampola miraculosa, experimentação com a novela gráfica e a collage. A rigor, o que se tem é, mais uma vez, uma apropriação pessoal de técnica tomada de empréstimo das artes visuais - especifi- 
camente a reutilização de materiais impressos -, acrescida da inserção de uma "legenda" para cada uma das imagens apresentadas.

Tais "legendas" podem tanto iluminar a informação visual apresentada, como obscurecer seu sentido, vez que o icônico e o verbal se encontram aqui liberados do compromisso de um encontro pontual. De qualquer forma, do conjunto das páginas se depreende uma progressão narrativa gerada pelas imagens e pelas palavras, ainda que esta progressão não seja de tipo linear, sendo interessante notar como se processa o algoritmo desta progressão narrativa criada a partir das convergências e das colisões entre imagem e palavra.

Para Clara Rocha, a collage também seria o princípio constitutivo de poemas como "O poema pouco original do medo", construídos a partir de uma "longa sequência de imagens" (ROCHA, 1982, p. 18), como se percebe nos versos de abertura:

\author{
O medo vai ter tudo \\ pernas \\ ambulâncias \\ e o luxo blindado \\ de alguns automóveis
}

Vai ter olhos onde ninguém os veja mãozinhas cautelosas enredos quase inocentes ouvidos não só nas paredes mas também no chão no teto no murmúrio dos esgotos e talvez até (cautela!) ouvidos nos teus ouvidos (O’NEILL, 1981, P. 143).

Segundo a mesma comentadora, "uma forma específica de colagem são os trechos compostos por sequências de flashes, como por exemplo 'Seios' ou 'Mãos'” (ROCHA, 1982, p. 18), de que reproduzimos excertos:

Quem comparou os seios que são teus (Banal imagem) a colinas!

Com donaire, avançam os teus seios.

Ó minha embarcação!

$(\ldots)$

Seios adivinhados, entrevistos, Jamais possuídos, sempre desejados! 
"Oculta, pois, oculta esses objetos

Altares onde fazem sacrifícios

Quantos os vêem com olhos indiscretos"

Raparigas dos limões a oferecerem

Frita mais atrevida: inesperados seios...

(...)

Engolfo-me num seio até perder

Memória de quem sou...

Quantos seios devorou a guerra, quantos, Depressa ou devagar, roubou à vida,

À alegria, ao amor, às gulosas

Bocas dos miúdos

Pouso a cabeça no teu seio

E nenhum desejo me estremece a carne.

Vejo os teus seios, absortos

Sobre um pequeno ser.

(O’NEILL, 1981, p. 100-104)

Certas mãos ociosas como peixes

num aquário de melancolia.

Com as duas mãos apodero-me de ti,

retomo o teu corpo e com ele me entendo.

A pureza com a sua carga negra,

penosamente vou definindo-a,

nesta mão que lanço e que me precipita,

que me nega e afirma

(...)

Barbeiro que com tua mão

mole

pões esse pássaro de ferro

a cantar na minha cabeça,

não me fales de futebol

e com a mesma mão mole

faz-me a barba que tenho pressa!

(O’NEILL, 1981, p. 107-109).

Depois de tratarmos da ékphrasis e da fanopeia, resta, ainda, a iconicização do signo verbal.

Antes de analisarmos os textos de Alexandre O'Neill que expressam esse processo semiótico, é de bom alvitre retomar, ainda que de forma sucinta, certos conceitos advindos das categorias propostas pelo filósofo norte-americano Charles Sanders Peirce a partir dos quais se lastreia nossa interpretação. 
Peirce dividia os signos em ícones, índices e símbolos. Os símbolos seriam convenções - portanto, signos com poder de lei (legissignos), a serem chamados de terceiridade ("thirdness"). Os índices relatariam uma relação de materialidade e presença física (de tipo indicial, sinalizadora, indicando) entre coisa e signo, integrando os domínios da secundidade ("secondness"). Finalmente, os ícones seriam o primado das formas e dos sentimentos (primeiridade, "firstness") - e, assim, se constituiriam na matéria-prima dos processos semióticos deflagrados pela arte (cf: PIGNATARI, 2004, p. 59). O que chamamos de iconicização nada mais é que o processo de metamorfose de um signo arbitrário e coercitivo (um legissigno, pertencente aos domínios da thirdness) em forma pura (um ícone, pertencente aos domínios da firstness).

Essa metamorfose é representada pela série de poemas "Divertimento com sinais ortográficos", recolhida no livro Abandono vigiado, de Alexandre O'Neill.

Como propunha Adorno, em seu ensaio Sinais de pontuação (ADORNO, 2003, p. 141-149), os sinais ortográficos são tanto hieróglifos em trânsito no interior da linguagem como marcações visuais que nos lembram das relações (possíveis e impossíveis) entre a linguagem verbal e seu antípoda - especificamente a música, que, como os artes visuais, se situa perante a literatura como alteridade. Se a palavra é sempre símbolo (portanto: convenção, coerção, thirdness), o que esta série tenta fazer é o caminho de volta, revertendo-a em índice (secondness) e, finalmente, em ícone (firstness, primado da imagem e do som).

Assim, no "Divertimento", temos uma série de vinte e oito poemas, sendo que cada um ostenta um sinal ortográfico e um texto.

O extrato verbal deixa de impor relações lógicas com o sinal gráfico e passa a estabelecer relações analógicas, a considerá-lo em seu aspecto fisionômico - ou seja: não mais como sinal que expressa uma convenção, e sim como uma figura. Isso ocorre, por exemplo, com o sinal gráfico de parágrafo, que é lido como um cisne ou um hipocampo. O sinal de circunflexo é lido como um chapéu. O til é uma sobrancelha ou uma andorinha.

Em outras ocasiões, o comentário verbal se ocupa em estabelecer uma relação metalinguística com o sinal gráfico, não raramente pautada pelo humor. Assim, a cedilha seria uma vírgula que decaiu de classe social. O ponto final se apresenta como um tipo policial cuja função é defender os textos e que, depois dele, só admite maiúscula ou espaço em branco.

Depois de ler o que era signo convencional (legissigno) como figura (ícone), temos, portanto, um processo de resgate das camadas indiciais (índice) dos mesmos sinais ortográficos. E, instaurada esta instância metalinguística nos poemas, ela nos faz lembrar que toda produção de linguagem implica em reprodução de ideologia. 
É assim que, com seu característico humor, a poética de O’Neill provoca nos sinais ortográficos uma independência lógico-semântica, deslocando-os de sua função mimética original e, ao mesmo tempo, satirizando aquilo que Adorno chama de reverência feita pela escrita ao que ela sufoca. É assim que os sinais ortográficos - em sua função prosaica de reprimir determinados comportamentos da escrita (caso do ponto final, que, intolerante, como bem frisa O'Neill, só admite depois de si o espaço em branco ou a letra maiúscula) - revelam a dimensão coercitiva da linguagem.

Como já ressaltou Clara Rocha, a libertação do material artístico é nuclear na poética de O’Neill. Por esta razão, nada mais consequente que esta libertação dos sinais ortográficos ser atingida mediante a iconicização do signo verbal.

Saliente-se que ela é feita com notável senso lúdico, já que o próprio jogo é uma forma de reorganização da realidade a partir de valores outros que os da sociedade de acumulação.

De igual forma, cumpre lembrar o especial interesse que Freud manifestou por jogos de linguagem ou ainda o fato de que, a partir da segunda metade do século XX, se intensificarão as investigações no território da psicanálise sobre as relações entre jogo e criatividade, de que fazem testemunho obras de Winnicott, Hanna Segall e Marion Milner. Segundo Winnicott, o jogo tem o poder de colocar crianças e adultos num estado de liberdade muito próximo ao da criação - e, para o psicanalista inglês, o indivíduo só descobre sua persona quando se mostra criador.

Segundo Clara Rocha, “uma boa parte da poesia de O’Neill é jogo, e por isso provoca em nós (e provoca-nos para) um certo modo de leitura" (ROCHA, 1982, p. 18). Com a entrada em cena da lógica do jogo, "temos uma vez mais ruptura das regras, com as palavras postas em festa e com a alegria assumida dessas palavras" (ROCHA, 1982, p. 18).

Nesse ponto, mais uma vez é instrutivo recorrer aos conceitos preconizados pela semiótica de Peirce, a fim de compreender melhor o que está em questão. Ao fazer o caminho inverso da ordem semiótica habitual - ou seja: partindo de um signo convencional (terceiridade; legissigno) para chegar numa forma visual (primeiridade; ícone), seguindo, portanto, a ordem decrescente -, os poemas lúdicos de O’Neill nos fazem lembrar que a palavra poética implica descondicionamento das rotinas linguísticas. Ao caminhar das generalizações coercitivas (palavra em estado de chumbo) do legissigno rumo às possibilidades múltiplas e à indeterminação do ícone - já que esta última qualidade de signo "labora no campo do possível e do indeterminado" (PIGNATARI, 2004, p. 57) -, verifica-se o retorno do horizonte utópico já desfraldado pela ékphrasis, mas agora apresentando outra proposição: a palavra poética, carregada de uma intenção lúdica (que 
é, em grande medida, resposta à busca reiterada de um lidar com o signo verbal enquanto meio de reencantamento do mundo), retomaria, em seu transporte mercurial, a capacidade de descondicionar o ser, ora preso na malha imobilizadora tramada por suas rotinas (que, em última instância, são sintoma de falsa consciência), mesmo nos domínios da linguagem.

Desse modo, a série "Divertimento com sinais ortográficos", sob a superfície enganosa da simplicidade técnica, reafirma a necessidade de a poesia - como toda forma de saber - se conduzir à alegria, enquanto gaia ciência, provando que é possível, pelo fazer poético, reverter o curto-circuito conceitual gerado pela linguagem em seu modo de funcionamento prosaico, binário e excludente. Se, como ensina a psicanálise, todo problema de gozo é um problema de linguagem, é necessária a libertação lúdica da própria linguagem.

Tanto o "Divertimento" de O'Neill como a ékphrasis cesarinyana e, de modo mais amplo, a poesia em regime fanopaico, acenam para formas utópicas de relacionamento da palavra com outros campos do saber e do fazer, formas estas que reafirmam a importância da palavra poética enquanto modo de conhecimento e de abordagem da realidade sobre a qual nos deslocamos e cujas manifestações sensíveis são compartilhadas por todos os homens.

\section{REFERÊNCIAS BIBLIOGRÁFICAS}

ADORNO, T. W. Notas de Literatura I [Noten zur Literatur]. São Paulo: Ed. 34: Duas Cidades, 2003.

ARISTÓTELES. Poética. Lisboa: Imprensa Nacional, 2003.

BRANDÃO, Roberto de Oliveira. As figuras de linguagem. São Paulo: Ática, 1989.

BUCHS, Arnaud. Écrire le regard. L'esthétique de la Modernité en question. Paris: Hermann, 2010.

CARONE, Modesto. Metáfora e montagem. São Paulo: Perspectiva, 1974.

CESARINY, Mario. Primavera autônoma das estradas. Lisboa: Assírio \& Alvim, 1980.

. Vieira da Silva Arpad Szenes ou O Castelo Surrealista. Lisboa: Assírio \& Alvim, 1984.

DIDEROT, Denis. Carta sobre os surdos-mudos para uso dos que ouvem e falam [Lettre sur les sourds et muets à l'usage de ceux qui entendent et qui parlent]. São Paulo: Nova Alexandria, 1993. 
FLUSSER, Vilém. Filosofia da caixa preta. Rio de Janeiro: Relume Dumará, 2009.

HORÁCIO. "Arte poética (Epistula ad Pisones)". In: A Poética Clássica. São Paulo: Cultrix: EDUSP, 1981.

LICHTENSTEIN, Jacqueline (org.). A pintura. Volume VII: O paralelo das artes [La Peinture]. São Paulo: Ed. 34, 2005.

LOPES, Anchyses Jobim. Estética e Poesia - imagem, metamorfose e tempo trágico. Rio de Janeiro: Sette Letras, 1995.

LOURENÇO, Eduardo. Tempo e Poesia - à volta da literatura. Lisboa: Relógio d'Água, 1987.

LYOTARD, Jean-François. Discours, figure. Paris: Éditions Klinkensieck, 1985.

MITCHELL, W. J. T. Teoría de la imagen [Picture Theory: Essays on Verbal and Visual Representation]. Madrid: Akal, 2009.

MUHANA, Adma. Poesia, e Pintura ou Pintura, e poesia: tratado seiscentista de Manuel Pires de Almeida. São Paulo: Edusp, 2002.

O’NEILL, Alexandre. A Ampola Miraculosa. Lisboa: Assírio \& Alvim, 2002.

Poesias Completas 1951-1981. Lisboa: Imprensa Nacional, 1982.

PAZ, Maria José. Figuras e figurações. Lisboa: Assírio \& Alvim, 2000.

PEIRCE, Charles Sanders Peirce. Semiótica. São Paulo: Perspectiva, 1999.

POUND, Ezra. $A B C$ da Literatura [ABC of Reading]. São Paulo: Cultrix, 1970.

. A arte da poesia - ensaios escolhidos. São Paulo: Cultrix, 1988.

ROCHA, Clara. “Prefácio”. In: O'NEILL, Alexandre. Poesias Completas 1951-1981. Lisboa: Imprensa Nacional, 1982.

WINNICOTT, D. W. O brincar e a realidade [Playing and reality]. Rio de Janeiro: Imago, 1975.

Recebido para publicação em 30/05/12.

Aprovado em 30/06/2012. 